\section{KẾT LUẬN}

Qua kết quả nghiên cứu, đánh giá 51 đối tượng loét hành tá tràng HP $(+)$ đến khám tại khoa tiêu hóa bệnh viện Bạch Mai chúng tôi có kết luận như sau, đây là phác đồ tiệt trừ HP đạt hiệu quả cao và gặp ít tác dụng không mong muốn.

\section{TÀI LIỆU THAM KHẢO}

1. De Francesco, $\mathbf{V}_{\text {., }}$ et al., Sequential treatment for Helicobacter pylori does not share the risk factors of triple therapy failure. Aliment Pharmacol Ther, 2004. 19(4): p. 407-14.

2. Vaira, $D_{.}$, et al., Sequential therapy versus standard triple-drug therapy for Helicobacter pylori eradication - A randomized trial. Annals of internal medicine, 2007. 146: p. 556-63.

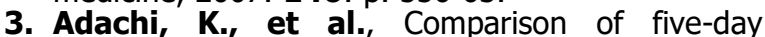
Helicobacter pylori eradication regimens: rabeprazole-based and omeprazole-based regimens with and without omeprazole pretreatment. Current Therapeutic Research, 2003. 64(7): p. 412-421.

4. Malfertheiner, $\mathbf{P}_{\text {., }}$ et al., Current concepts in the management of Helicobacter pylori infection: the Maastricht III Consensus Report. Gut, 2007. 56(6): p. 772-81.

5. Garza González, E., et al., [Helicobacter pylori erradication and its relation to antibiotic resistance and CYP2C19 status]. Rev Esp Enferm Dig, 2007. 99(2): p. 71-5.

\title{
MộT Số YẾU TỐ NGUY CƠ VÀ VÔI HOÁ MACH VÀNH TRÊN CLVT 256 DÃY
}

\author{
Nguyễn Đình Minh*, Hoàng Văn Hậu**, Nguyễn Thanh Vân*
}

\section{TÓM TẮT}

Mục tiêu: nghiên cứu một số yếu tố nguy cơ liên quan vôi hoá mạch vành trên CLVT-256 dãy. Đối tượng và phướng pháp: nghiên cứu mô tả cắt ngang các trường hợp được chup CLVT 256 mach vành từ tháng 3 đến 7/2021. Kết quả: $545 \mathrm{BN}$ gồm 261 nam và 264 nữ. Tuổi trung vị là 72 tuổi (63-79), thấp nhất là 39 và cao nhất là 100 tuổi); trong đó tuố trung vị của nam là 71 tuổi (60-79) thấp hơn của nữ là 73 tuổi $(65-80)(p<0,01)$. Về nguy cơ, nam giới có tỉ lệ uống rượu $(24,1 \%)$ cao hơn ở nữ giới $(1,8 \%)$ với tý suất chênh OR: 17,8 [95\%CI: 7,0-44,9] $(p<0,01)$. Mặt khác, tỉ lê nam giới hút thuốc lá $(20,3 \%)$ cũng cao hơn so với nữ giới $(2,1 \%)$ với tỷ suất chênh OR: 11,8 $[95 \% \mathrm{CI}=5,0-28,0](p<0,01)$. Trên chup CLVT 256 dãy có 341 BN có VHMV, chiếm $62,6 \%$. Về vôi hoá, tỷ lệ VHMV ở BN > 60 tuổi $(70,2 \%)$ là cao hơn những $B N$ $\leq 60$ tuổi $(31,1 \%)(p<0,01)$, tỷ suất chênh hồi quy đa biến là 6,0 [95\%CI: $3,7-9,9](p<0,01)$. Nam giới có tỉ lệ VHMV (67\%) cao hơn so ở nữ giới $(58,5 \%)$ $(p=0,04)$, trong đó tỉ suất chênh của hồi quy đa biến là 1,8 [95\%CI: 1,2-2,7] $(\mathrm{p}<0,01)$. Mặt khác, các $B N$ cao huyết áp có tỉ lệ VHMV $(69,4 \%)$ cao hớn so với nhóm không cao huyết áp $(55,8 \%)$, tỷ suất chênh hồi quy đơn biến là $1,8[1,3-2,5](p<0,01)$, và tỉ lệ VHMV ở BN đái đường (74\%) cao hơn các trường hợp không mắc bệnh này $(60,1 \%)$ với tỷ suất chênh hồi quy đơn biến là $1,8[1,2-3,1](\mathrm{p}=0,01)$. Tuy nhiên, hai yếu tố này không thấy có liên quan ý nghĩa với VHMV trong kết quả phân tích hồi quy đa biến $(p>0,05)$. Kết

\footnotetext{
*Bệnh viện hữu nghi Việt Đức

**Trường Đại hoc y Hà Nội

Chịu trách nhiệm chính: Nguyễn Đình Minh

Email: minhdr24@gmail.com

Ngày nhận bài: 18.10.2021

Ngày phản biên khoa họ: 13.12.2021

Ngày duyệt bài: 24.12.2021
}

luận: Vôi hoá mạch vành có liên quan ý nghĩa đến các yếu tố về tuổi, giới, cao huyết áp và đái tháo đường.

Từ khoá: vôi hoá mạch vành, CLVT-256 dãy, yếu tố nguy cơ.

\section{SUMMARY \\ RISK FACTORS AND CORONARY ARTERY CALCIFICATION ON 256 SLIDE CT-SCANNER}

Objectives: study some risk factors related to coronary artery calcification (CAC) on CT-256 slices. Subjects and methods: a cross-sectional descriptive study of coronary angiogram on CT 256 slices from March to July 2021. Results: total 545 patients, including 261 male and 264 female. Median age was 72 years (63-79), from 39 to 100 years old; in which the median age of male is 71 years old $(60-79)$ lower than that of female, 73 years old $(65-80)(p<0.01)$. Regarding the risks, men were more likely to drink alcohol $(24.1 \%)$ than women (1.8\%) with an odds ratio: 17.8 [95\% CI: 7.0-44.9] ( $p<0.01)$. On the other hand, the percentage of men who smoking (20.3\%) was also higher than that of women $(2.1 \%)$ with odds ratio: 11.8 [95\%CI $=5.0-28.0$ ] $(p<0.01)$. On CT 256 slices, there were 341 patients with CAC, accounting for $62.6 \%$. The incidence of CAC in 60-years-old and over group (70.2\%) was higher than in the younger group $(31.1 \%) \quad(p<0.01)$, multivariable regression odds ratio was 6,0 [95\%CI: $3.7-9.9](p<0.01)$. Men had a higher rate of CAC (67\%) than women $(58.5 \%)$ $(p=0.04)$, in which the odds ratio of multivariable regression was 1.8 [95\%CI: $1,2-2,7](p<0.01)$. Moreover, the hypertensive patients had a higher rate of CAC $(69.4 \%)$ than the nortensive group $(55.8 \%)$, the univariate odds ratio was $1.8[1.3-2.5](p<0.01)$, and the prevalence of CAC in diabetic patients $(74 \%)$ was higher than in patients without diabetes $(60.1 \%)$ with univariate odds ratio of $1,8[1,2-3,1](p=0.01)$. However, these two factors were not found to be significantly related to CAC in the results of multivariable regression analysis $(p>0.05)$. 
Conclusion: Coronary artery calcification is significantly related to age, gender, high blood pressure and diabetes.

Keywords: coronary artery calcification, CT-256 slices, risk factors.

\section{I. ĐẠT VẤN ĐỀ}

Vôi hoá mạch vành (VHMV) từ lâu đã được biết là có liên quan đến nguy cơ gây bệnh mạch vành. Bệnh có thể tiến triển âm thầm trong thời gian dài hoặc đột ngột biểu hiện lâm sàng đe doa tính mang người bệnh. Các nghiên cứu trước đây cho thấy những trường hợp không có VHMV thì nguy cơ xảy ra các biến cố mạch vành cấp tính là rất thấp. Do vậy, chẩn đoán VHMV là rất quan trọng nhằm phòng ngừa và hạn chế những biến cố tim mạch xảy ra.

Theo nghiên cứu trước đây [1],[2], các nguy cơ VHMV có thể là tuổi, giới, chỉ số khối cơ thể (BMI- Body mass index), cao huyết áp, đái tháo đường, rối loạn mõ̃ máu, hút thuốc lá... Sự kết hợp các yếu tố này sẽ làm tăng khả năng VHMV, tăng nguy cơ đột quỵ cho người bệnh.

Phương pháp tính điểm vôi hoá bằng thang điểm Agatston trên CLVT được ứng dụng rộng rãi trong đánh giá mức độ VHMV. Cắt lớp vi tính 256 dãy (CLVT-256) có độ phân giải và tốc độ vượt trội hơn so với các thế hệ máy chụp trước đó. Do vậy, CLVT-256 được cho là có khả năng phát hiện VHMV tốt hơn và không bị ảnh hưởng nhiều bởi các yếu tố nhiễu do nhịp tim nhanh hoặc không đều.

Do vậy, chúng tối tiến hành nghiên cứu này nhằm mục tiêu: "đánh giá sự liên quan giữa một số yêu tố nguy cơ thường gặp và vôi hoá mạch vành ơ các trường hợp được chụp CLVT-256 dãy".

\section{II. ĐỐI TƯỢNG VÀ PHƯƠNG PHÁP NGHIÊN CỨU}

2.1. Đối tượng nghiên cứu: Gồm các bênh nhân (BN) có nghi ngờ bệnh mạch vành (BMV) được chụp CLVT-256 mạch vành tại khoa Chẩn đoán hình ảnh - Bệnh viện hữu nghị Việt Đức trong từ tháng 3 đến 7/2021.

- Tiêu chuẩn lứa chon: BN được chụp CLVT256 mạch vành, có đo điểm vôi hóa Agatston, tuổi từ 18 trở lên, không phân biệt giới tính.

- Tiêu chuẩn loại trừ: không lựa chọn các trường hợp chất lượng hình ảnh khổng đạt yêu câu, đã được đặt stent mạch vành hoăc can thiệp nong mạch vành trước đó, sau phẫu thuật lồng ngực.

\subsection{Phương pháp nghiên cứu:}

- Phương pháp nghiên cứu: Nghiên cứu mô tả cắt ngang.

- Phương tiện nghiên cứu: Máy chụp Cắt lớp vinh tính 256 dãy (hãng General Electrics) có phần mềm chụp mạch vành, dựng ảnh và đo điểm vôi hoá.

- Các thông tin thu thập gồm: tuổi, giới, chiều cao, cân nặng, tiền sử cao huyết áp, đái tháo đường, hút thuốc lá, uống rượu...

- Quy trình chụp CLVT-256 mạch vành: bệnh nhân được hướng dẫn nhịn ăn ít nhất 6 giờ trước khi chụp, nhịp tim ổn định được điều chỉnh không quá 90 chu kỳ/phút, không có loạn nhịp tim. Chụp các lát cắt không tiêm thuốc khu trú vùng tim kéo dài từ nền tim lên đến đỉnh tim khi bênh nhân hít vào sâu và nhịn thở để đánh giá độ rõ nét của hình ảnh và tính điểm vôi hóa mạch vành. Dữ liệu hình ảnh thu ở thì cuối tâm trương ( $75 \%$ của khoảng R-R). độ dày lớp cắt là $5 \mathrm{~mm}$, tái tạo hình ảnh có độ dày là $0,625 \mathrm{~mm}$. Vôi hoá các nhánh mạch vành được đánh giá và đo đặc bằng phần mềm trên máy chụp CLVT -256.

- Các biến số nghiên cứu gồm: Tuổi: năm 2021 - năm sinh; giới: nam hoặc nữ; chiều cao: đơn vị tính tính bằng centimet $(\mathrm{cm})$; cân nặng: đơn vị tính bằng kilogram $(\mathrm{kg})$; Béo phì: khi BMI $>23$ (chỉ số BMI = chiều cao/(cân nặng) ${ }^{2}$; cao huyết áp: khi huyết áp tối thiểu $>90 \mathrm{mmHg}$ hoặc huyết áp tối đa $>140 \mathrm{mmHg}$; hút thuốc lá khi có hút thuốc trong thời gian dài; uống rượu; đái tháo đường: dựa vào bệnh sử hoặc xét nghiệm đường huyết

- Thống kê và xử lý số liệu: bằng phần mềm SPSS 20.0.

\section{KẾT QUẢ NGHIÊN CỨU}

\section{1. Đăc điểm chung của nhóm nghiên cứu:}

Tuổi và giới tính: gồm 545 bệnh nhân (BN) với 261 nam và 264 nữ, tỷ lệ nam: nữ là $1: 1$. Trung vị là 72 tuổi (63-79), (thấp nhất là 39 tuổi và cao nhất là 100 tuổi); trong đó tuổi trung vị của nam là 71 tuổi (60-79) và của nữ là 73 tuổi (65-80) sự khác về độ tuổi giữa nam và nữ là có ý nghĩa thống kê $(p<0,01)$.

Yếu tố nguy cơ của nhóm nghiên cứu:

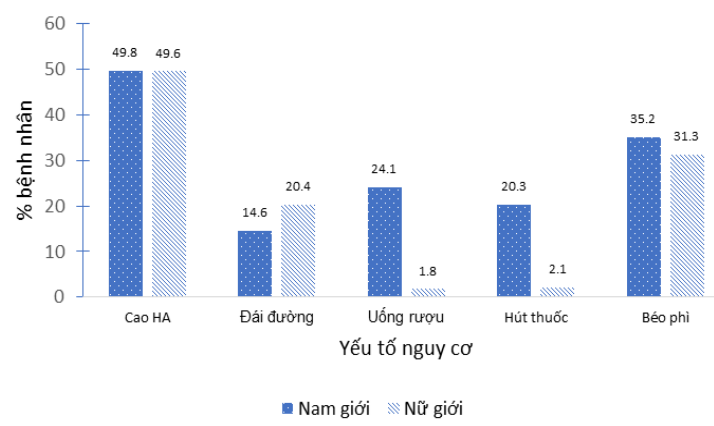

Biểu đồ 1. Tỷ lệ các yếu tố nguy cơ theo giới tính $(n=545)$ 
Nam giới có tỉ lệ uống rượu là 63/261 $(24,1 \%)$ cao hơn nhiểu lần so với nữ giới là $5 / 264$ (1,8\%) với $p<0,01$ (OR:17,8, 95\%CI: 7,044,9). Mặt khác, tỉ lệ hút thuốc của nam giới là $53 / 261(20,3 \%)$ cũng cao hơn nhiêu so với nữ giới 6/264 (2,1\%) với $\mathrm{p}<0,01$ (OR: 11,8,95\%CI $=5,0-28,0$ ) (biểu đồ 1 ).

Chúng tôi không thấy có sự khác biệt ý nghĩa về tỉ lệ cao huyết áp, đái tháo đường hay béo phì giữa nam và nữ $(P>0,05)$ (biểu đồ 1$)$.

\section{2. Đặc điểm vôi hoá mạch vành và yếu tố nguy cơ}

\section{Bảng 1. Các yếu tố nguy cơ và vôi hoá mach vành $(n=545)$}

\begin{tabular}{|c|c|c|c|c|c|c|c|}
\hline \multirow{3}{*}{\multicolumn{2}{|c|}{ Yếu tố nguy cơ }} & \multicolumn{4}{|c|}{ Vôi hoá mạch vành } & \multirow{3}{*}{$\begin{array}{c}\text { OR } \\
(95 \% \mathrm{CI})\end{array}$} & \multirow{3}{*}{$\mathbf{p}$} \\
\hline & & \multirow{2}{*}{\multicolumn{2}{|c|}{ (n) }} & \multicolumn{2}{|c|}{ Không vôi } & & \\
\hline & & & & (n) & $(\%)$ & & \\
\hline \multirow{2}{*}{ Tuổi } & $>60$ & 308 & 70,2 & 131 & 29,8 & 5,2 & $<0,01$ \\
\hline & $\leq 60$ & 33 & 31,1 & 73 & 68,9 & $3,3-8,2$ & \\
\hline \multirow{2}{*}{ Giới } & Nam & 175 & 67 & 86 & 33 & 1,45 & 0,04 \\
\hline & Nữ & 166 & 58,5 & 118 & 41,5 & $1,0-2,1$ & \\
\hline \multirow{2}{*}{ Cao huyết áp } & Có & 188 & 69,4 & 83 & 30,6 & 1,8 & $<0,01$ \\
\hline & Không & 153 & 55,8 & 121 & 44,2 & $1,3-2,6$ & \\
\hline \multirow{2}{*}{$\begin{array}{c}\text { Đái tháo } \\
\text { đường }\end{array}$} & Có & 71 & 74 & 25 & 26 & 1,9 & 0,01 \\
\hline & Không & 270 & 60,1 & 179 & 39,9 & $1,2-3,1$ & \\
\hline \multirow{2}{*}{ BMI } & $<23$ & 116 & 64,1 & 65 & 35,9 & 1,1 & 0,61 \\
\hline & $\geq 23$ & 225 & 61,8 & 139 & 38,2 & $0,8-1,6$ & \\
\hline \multirow{2}{*}{ Uống rượu } & Có & 45 & 66,2 & 23 & 33,8 & 1,2 & 0,51 \\
\hline & Không & 296 & 62,1 & 181 & 37,9 & $0,70-2,0$ & \\
\hline \multirow{2}{*}{ Hút thuốc } & Có & 39 & 66,1 & 20 & 33,9 & 1,2 & 0,55 \\
\hline & Không & 302 & 62,1 & 184 & 37,9 & $0,7-2,1$ & \\
\hline
\end{tabular}

Giải thích: OR: tỉ suất chênh, BMI: chỉ số khối cơ thể. 95\%CI: khoảng tin cậy 95\%

Trên CLVT 256 dãy, có 341/545 BN có VHMV, chiếm $62,6 \%$. Các $B N>60$ tuổi có tỉ lệ VHMV là $308 / 439$ (70,2\%) cao hơn so với 33/106 (31,1\%) $\mathrm{BN} \leq 60$ tuổi, sự khác biệt là có ý nghĩa thống kê với $p<0,01$ (OR: 0,52; 95\%CI: 3,29-8,23). Mặt khác, nam giới có tỉ lệ VHMV là 175/261 (67\%) cao hơn so với nữ giới là $166 / 284(58,5 \%)$ với $\mathrm{p}=0,04$ (OR: 1,45; 95\%CI: 1,02-2,05). Bên cạnh 188/271 (69,4\%) cao hơn so với nhóm không cao huyết áp là $153 / 274 \quad(55,8 \%)$ với p<0,01(OR:1,79: 95\%CI: 1,26-2,55). Tỉ lệ VHMV ở các BN đái tháo dường là 71/96 (74\%) cũng lớn hơn ở các $\mathrm{BN}$ không đái tháo đường là 270/449 (60,1\%) với $\mathrm{p}=0.01$ (OR: $1,9,95 \% \mathrm{CI}$ : 1,2-3,1) (bảng 1).

Chúng tôi không thấy có sự khác biệt về tỉ lệ VHMV giữa các nhóm béo phì, hút thuốc hay uống rượu $(p>0,05)$ (bảng 1). đó, các $\mathrm{BN}$ cao huyết áp có tỉ lệ vôi hoá là

Bảng 2. hồi quy logistic VHMV và các yêu tố nguy cơ $(n=545)$

\begin{tabular}{|c|c|c|c|c|}
\hline Yếu tố́ & OR thô (95\%CI) & $\mathbf{p}$ & OR hiệu chỉnh (95\%CI) & $\mathbf{p}$ \\
\hline$>60$ tuối & $5,2(3,3-8,2)$ & $<0,01$ & $6,0(3,7-9,9)$ & $<0,01$ \\
\hline Nam giới & $1,5(1,0-2,1)$ & 0,04 & $1,8(1,2-2,7)$ & $<0,01$ \\
\hline Cao huyết áp & $1,8(1,3-2,5)$ & $<0,01$ & $1,5(0,9-2,1)$ & 0,06 \\
\hline Đái đường & $1,8(1,2-3,1)$ & 0,01 & $1,4(0,8-2,4)$ & 0,24 \\
\hline Uống rượu & $1,2(0,7-2,0)$ & 0,51 & $1,3(0,6-2,8)$ & 0,54 \\
\hline Hút thuốc & $1,2(0,7-2,1)$ & 0,55 & $1,1(0,5-2,6)$ & 0,76 \\
\hline BMI<23 & $1,1(0,76-1,6)$ & 0,61 & $1,3(0,8-1,9)$ & 0,28 \\
\hline
\end{tabular}

Giải thích: OR: tỷ suất chênh, $95 \% \mathrm{CI}$ : khoảng tin cây 95\%, BMI: chí số khối cơ thể

Kết quả phân tích hồi quy logistic đơn biến và đa biến về một số yếu tố liên quan đến VHMV ở các bệnh nhân được nghiên cứu. Vôi hoá mạch vành có mối liên quan đến nhóm nam giới dựa kết quả phân tích logistic cả đơn biến và đa biến với tỉ xuất chênh tương ứng là $1,5(95 \% \mathrm{CI}: 1,0-$ $2,1, \mathrm{p}=0,04)$ và 1,$8 ;(95 \% \mathrm{CI}: 1,2-2,7, \mathrm{p}<0,01)$.
Vôi hoá cũng thấy có liên quan đến nhóm $>60$ tuổi với tỉ suất chênh tương ứng là $5,2(95 \% \mathrm{CI}$ : $3,3-8,2, \quad p<0,01)$ và $6,0 \quad(95 \% \mathrm{CI}: \quad 3,7-9,9$, $p<0,01)$. Mặt khác, chúng tôi thấy có sự liên quan giữa VHMV với cao huyết áp và đái tháo đường với tỉ suất chênh trên logistic hồi quy đơn biến tương ứng là 1,8 (95\%CI: $1,3-2,5, \mathrm{p}<0,01)$ và $1,8(1,2-3,1, \mathrm{p}=0,01)$, nhưng không thấy $c 0$ sự liên quan ý nghĩa trên kết quả hồi quy đa biến 
( $p>0,05)$. Thêm vào đó, chúng tôi không thấy sự liên quan có ý nghĩa thống kê giữa VHMV với cao huyết áp, đái tháo đường hay béo phì (bảng 2).

\section{BÀN LUÂN}

Bệnh lý mạch vành là một trong những nguyên nhân hàng đầu gây tử vong trên thế giới. Các yếu tố như xơ vữa, vôi hoá là những căn nguyên hay gặp nhất, làm hẹp mạch vành gây thiếu máu cơ tim, dẫn đến tàn tật hoặc tử vong. Phát hiện VHMV giúp xác định nguy cơ thiếu máu cơ tim, từ đó, có biện pháp phòng ngừa hay điều trị tích cực để hạn chế tối đa những biến chứng xảy ra.

Theo các nghiên cứu trước đây, mức độ VHMV được cho là có liên quan đến các yếu tố nguy cơ truyền thống như: tuổi cao, nam giới, hút thuốc lá, cao huyết áp, đái tháo đường, suy thận, rối loạn mõ̃ máu, béo phì, ít hoạt động thể lực [3], [4], [5], [6], [7]. Theo Nasir K. và cs [8], các trường hợp có VHMV nặng sẽ làm tăng nguy cơ bệnh mạch vành gấp 8 lần so với các trường hợp có nhiều nguy cơ nhưng không có vôi hoá.

Vôi hoá mạch vành có liên quan đến các mảng xơ vữa. Vôi hóa xảy ra rất sớm trong quá trình xơ vữa động mạch vành. Vôi hoá hóa động mạch vành được đánh giá phổ biến nhất bằng chụp cắt lớp vi tính chùm điện tử hoặc chụp cắt lớp vi tính đa dãy. Các thành phân có tỉ trọng từ 130 HU (Housefil unit) trở lên được xem là vôi hoá.

Theo các nghiên cứu trước đây thì các $B N$ dưới 40 tuổi thường có tỉ lệ vôi hoá rất thấp, nên không được đưa vào trong nghiên cứu [2]. Trong nghiên cứu của chúng tôi, các BN có tuổi trung vị là 72 tuổi (63-79), thấp nhất là 39 và cao tuổi nhất là 100. Nghiên cứu của Lehman N. và cs [1], tuổi trung bình của các BN là $56,4 \pm$ 7,2 tuổi. Nghiên cứu của Nasir K. và cs [8] thì tuổi trung bình của các BN là $54 \pm 10$ tuổi. Như vậy, các $B N$ của chúng tôi cũng có độ tuổi cao hớn các nghiên cứu trước đây. Bên cạnh đó, tuổi trung vị của nam trong nghiên cưú 71 tuổi (6079) thấp hơn tuổi trung vị của nữ 73 tuổi (65-80) $(p<0,01)$. Điều đó có thể do nam giới thưởng có các biểu hiên liên quan đến bênh mạch vành sớm hơn nữ khiến bệnh nhân được khám và chụp CLVT.

Kết quả nghiên cứu cho thấy, nam giới có tỉ suất chênh về nguy cơ uống rượu gấp 17,8 lần so với nữ giới và nguy cơ hút thuốc gấp 11,8 lần $(p<0,01)$. Tuy vậy, chúng tôi không thấy có sự khác biệt về nguy cơ cao huyết áp, đái tháo đường hay béo phì giữa hai giới $(p>0,05)$.

Tuổi cao là yếu tố nguy cơ liên quan đến
VHMV ở cả hai giới nam và nữ [2]. Nghiên cứu của Jeevarethinam $A$. và cs [7] cũng cho thâý tỉ lệ VHMV tăng lên theo tuổi, đặc biệt là những người $\geq 60$ tuổi. Mặt khác, nghiên cứu của McClelland R.L. và cs [6] cho thấy nam giới có mức VHMV cao hơn nữ giới và số lượng và tỉ lệ vôi hoá tăng lên ở những người cao tuổi. Theo nghiên cứu của Oei $\mathrm{H}$. và cs [3], nam giới có tỉ lệ vôi hoá cao hơn rất nhiều nữ giới ở mọi độ tuổi. Điểm trung vị VHMV của nam thường cao gấp 5 lần ở nữ. Trong nghiên cứu này, tỷ lệ bệnh nhân có VHMV là $62,6 \%$ trường hợp, trong đó tỉ lệ VHMV ở nam giới là $67 \%$ cao hơn nữ giới ở cùng độ tuổi là $58,5 \%$, sự khác biệt là có ý nghĩa thống kê $(p=0,04)$. Bên cạnh đó, tỉ lệ VHMV ở nhóm $>60$ tuối $(70,2 \%)$ cũ̃ng cao hơn ở nhóm tuổi $\leq 60(31,1 \%)(p<0,01)$. Mặt khác, theo kết quả phân tích hồi quy logistic đơn biến và đa biến đều cho thấy tỉ suất chênh nguy cơ VHMV ở nam giới cao hơn gấp 1,5-1,8 lần nữ giới $(p<0,01)$. Nhóm tuổi $>60$ có tỉ suất chênh nguy cơ VHMV cao gấp 5,2 - 6 lần so với nhóm tuổi $<60(p<0,01)$. Như vậy kết quả nghiên cứu của chúng tôi cũng phù hợp với các nhận xét trước đây.

Cao huyết áp và đái tháo đường là những nguy cơ có tỷ lệ thuận với VHMV trong các nghiên cứu trước đây [3]. Theo Jampoum L.S. và cS [2] thì các trường hợp cao huyết áp có tỷ lệ VHMV và tỷ lệ phần trăm VHMV $\geq 70 \%$ cao hơn các trường hợp có huyết áp trong giới hạn bình thường. Theo Jeevarethinam $A$. và cs [7] thì tỉ lệ VHMV có liên quan ý nghĩa với thời gian mắc bệnh đái tháo đường. Mặt khác, những người mắc đái tháo đường, đặc biệt là đái tháo đường sau 40 tuổi (type II) thường có tỷ lệ mới mắc bệnh động mạch vành và đột quy cao hơn người bình thường. Bệnh cảnh kháng Insulin trong máu có thể gây tăng huyết áp và lắng đọng Cholesterol vào mảng xơ vữa động mạch.

Trong nghiên cứu của chúng tôi, tỉ lệ VHMV ở các BN cao huyết áp $(69,4 \%)$ là cao hơn và có sự khác biệt ý nghĩa với nhớm không cao huyết áp $(55,8 \%)(p<0,01)$. Mặt khác, tỉ lệ VHMV ở BN đái tháo đường $(74 \%)$ là cao hơn so với các trường hợp không mắc đái tháo đường $(60,1 \%)$ $(p=0,01)$. Kết quả phân tích hồi quy logistic đơn biến cũng cho thấy ở những $\mathrm{BN}$ cao huyết áp hay đái tháo đường thì có tỉ suất chênh về nguy cơ VHMV gấp 1,8 lần so với những trường hợp không mắc bệnh này $(p<0,01)$. Tuy nhiên, sự liên quan là chưa có ý nghĩa thống kê trên phân tích hồi quy đa biến $(p>0,05)$. Như vậy, cao huyết áp và đái tháo đường cũng là những yếu tố thuận lợi gây VHMV. 
Nghiên cứu trước đây cho thấy bệnh nhân hút thuốc sẽ có thời gian xuất hiện vôi hoá sớm hơn mười năm so với người khổng hút thuốc. Mặt khác, vôi hoá ở những người trước đây hút thuốc cũng xuất hiện sớm hơn, tuỳ thuộc vào thời gian hút thuốc và thời điểm cai thuốc và mức độ gia tăng này không có sự khác nhau về giới tính [1]. Bên cạnh đó, uống rượu có thể gây rối loạn chuyển hoá, cũng có nguy cơ gây xơ vữa và vôi hoá thành mạch. Mắt khác, thừa cân béo phì là khi chỉ số khối cơ thể BMI $\geq 23$. Chỉ số BMI cao chiếm khoảng 25-49\% bệnh động mạch vành ở các nước phát triển. Một số nghiên cứu cho thấy nguy cơ mắc bệnh động mạch vành ở nhóm béo phì cao gấp 3 lần nhóm có cân nặng bình thường.

Tuy nhiên trong nghiên cứu này, chúng tôi thây tỉ lệ vôi hoá động mạch vành ở những người uống rượu là $66,2 \%$, ở người uống hút thuốc là $66,1 \%$ và ở người béo phì là $61,8 \%$ là tương đối cao, nhưng không thấy khác biệt có ý nghĩa thống kê so với tỉ lệ VHMV ở các nhóm không mắc các nguy cơ này $(p>0,05)$. Bên cạnh đó, kết quả phân tích hồi quy logistic đa biến cũng cho thấy các trường hợp uống rượu, hút thuốc hay béo phì có nguy cơ mắc VHMV cao hơn nhưng sự khác nhau là chưa có ý nghĩa thống kê $(p>0,05)$.

\section{KẾT LUẬN}

Vôi hoá động mạch vành được phát hiện trên CLVT 256 dãy có liên quan đến một số yếu tố về lối sống và thể chất của từng cá nhân. Trong số đó, tuổi cao và nam giới là những yếu tố có liên quan đồng biến đến VHMV. Bên cạnh đó, các bệnh lý nền như cao huyết áp, đái tháo đường cũ̉ng làm gia tăng nguy cơ vôi hoá này.

\section{TÀI LIÊU THAM KHẢO}

1. Nils Lehmann, Stefan Möhlenkamp, Amir A. Mahabadi et al. (2014). Effect of smoking and other traditional risk factors on the onset of coronary artery calcification: Results of the Heinz Nixdorf recall study. Atherosclerosis, 232(2), 339-345.

2. L. S. Jamjoum, L. F. Bielak, S. T. Turner et al. (2002). Relationship of blood pressure measures with coronary artery calcification. Med Sci Monit, 8(12), Cr775-81.

3. H. H. Oei, R. Vliegenthart, A. Hofman et al. (2004). Risk factors for coronary calcification in older subjects. The Rotterdam Coronary Calcification Study. Eur Heart J, 25(1), 48-55.

4. Emil M. deGoma, Joshua W. Knowles, Fabio Angeli et al. (2012). The evolution and refinement of traditional risk factors for cardiovascular disease. Cardiology in review, 20(3), 118-129.

5. A. R. Folsom, G. W. Evans, J. J. Carr et al. (2004). Association of traditional and nontraditional cardiovascular risk factors with coronary artery calcification. Angiology, 55(6), 613-23.

6. R. L. McClelland, H. Chung, R. Detrano et al. (2006). Distribution of coronary artery calcium by race, gender, and age: results from the MultiEthnic Study of Atherosclerosis (MESA). Circulation, 113(1), 30-7.

7. A. Jeevarethinam, S. Venuraju, A. Dumo et al. (2017). Relationship between carotid atherosclerosis and coronary artery calcification in asymptomatic diabetic patients: A prospective multicenter study. Clin Cardiol, 40(9), 752-758.

8. K. Nasir, J. Rubin, M. J. Blaha et al. (2012). Interplay of coronary artery calcification and traditional risk factors for the prediction of allcause mortality in asymptomatic individuals. Circ Cardiovasc Imaging, 5(4), 467-73.

\section{KẾT QUẢ PHỤC HỒI CHỨC NĂNG KHỚP VAI SAU PHẪU THUẬT KHÂU RÁCH CHÓP XOAY KHỚP VAI}

\section{TÓM TẮT}

Mục tiêu: Đánh giá kết quả phục hồi chức năng khớp vai sau phẫu thuật nội soi khâu chóp xoay khớp vai. Phương pháp: can thiệp tiến cứu không có nhóm chứng; chọn mẫu toàn bộ được 58 người bệnh

\footnotetext{
*Bênh viện Việt Đức

**Trướng Đai họ Y Hà Nội

Chịu trách nhiệm chính: Đinh Ngọc Anh

Email: anhdn.dr@gmail.com

Ngày nhân bài: 28.10.2021

Ngày phản biện khoa học: 20.12.2021

Ngày duyệt bài: 30.12.2021
}

\section{Đinh Ngọc Anh*, Vũ Thị Bích Hạnh**}

sau phẫu thuật nội soi khâu rách chóp xoay khớp vai tai Bệnh viện Việt Đức từ 7/2020-5/2021. Đánh giá bằng Thang điểm khớp vai của Đại học California Los Angeles (UCLA) và đo tâm vận động khớp, thử cơ bằng tay. Người bệnh tập theo chương trình của Đại học California Los Angeleș. Người bệnh được tập tại viện từ ngày thứ 2 sau phâu thuật sau đó được hướng dẫn tập tại nhà có theo dõi đánh giá sau 3 tuần, 6 tuần và 12 tuần. Kết quả: Chức năng khớp vai sau phẫu thuật nội soi và phục hồi chức năng có sự tiến triển rõ rệt sau 3-6 và 12 tuần. Điểm UCLA trung bình đạt từ 11,98 tăng lên 26,07 (tối đa là 33 điểm). Cơ lực nhóm cơ chóp xoay và tầm vân đônng khớp vai sau 12 tuần đều được cải thiện có ý nghĩa. Kết luận: 